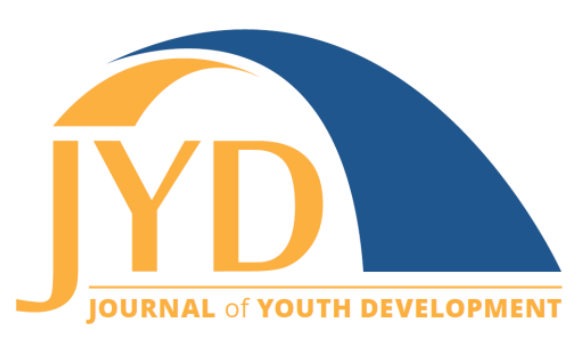

http://jyd.pitt.edu/ | Vol. 15 Issue 4 DOI 10.5195/jyd.2020.856 | ISSN 2325-4017 (online)

\title{
Volunteer Training Needs for Successful 4-H STEM Programs
}

\author{
Karen L. Franck \\ University of Tennessee, Department of Family and Consumer Sciences \\ kfranck@utk.edu \\ Joseph L. Donaldson \\ North Carolina State University, Department of Agricultural and Human Sciences \\ joseph_donaldson@ncsu.edu
}

\begin{abstract}
Informal STEM education programs through youth-serving organizations like 4-H have the potential to help youth prepare for future STEM careers. Volunteers continue to be an important way to mentor and provide programs for youth with support and guidance from professionals working for youth organizations. 4-H STEM programs present challenges for 4-H professionals and traditional 4-H volunteers who often have limited knowledge and confidence in their ability to teach STEM skills. Recruiting science experts as volunteers to lead 4-H STEM programs is one way to provide these programs, but some experts have limited knowledge about youth development and how to engage youth. Findings from the 4-H Science: Building a 4-H Career Pathway initiative are discussed here related to volunteer training, volunteer recruitment and retention and resources needed for 4-H professionals and volunteers to successfully implement 4-H STEM programs. A process evaluation was conducted that included focus groups and interviews in 3 states that participated in the initiative. Focus groups and interviews were conducted with youth, parents, volunteers, and 4-H professionals involved in 4-H STEM programs.

Themes included the need for volunteer training focused on increasing STEM knowledge and skills as well as pedagogy and youth engagement, the need for training for 4-H professionals related to STEM skills so they could support volunteer efforts, and the need to use diverse methods to recruit science experts and other volunteers for these programs.
\end{abstract}

Key words: 4-H, STEM, volunteer training, process evaluation, focus groups

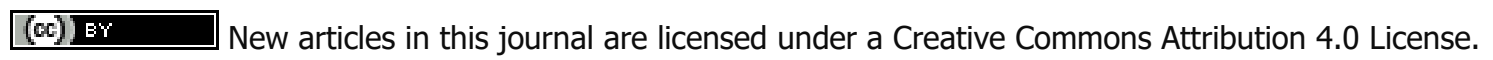
This journal is published by the University Library System, University of Pittsburgh and is cosponsored by the University of Pittsburgh Press. The Journal of Youth Development is the official peer-reviewed publication of the National Association of Extension 4-H Youth Development Professionals and the National AfterSchool Association. 


\section{Introduction}

Out-of-school time, informal STEM education has the potential to reinforce classroom science and to help youth prepare for future STEM careers to address the shortage of scientists in the workforce (Heck et al., 2012; Rothwell, 2014). On a national level, several youth-serving organizations, including 4- $\mathrm{H}$, are leaders in STEM learning (National Informal STEM Education Network, 2015). Adult volunteers serve an important role for these youth-serving organizations. Volunteers can provide positive mentoring relationships that can help engage youth in different STEM experiences and provide perspectives on potential educational tracks and careers. However, STEM projects can be challenging for youth-serving organizations to implement especially if their professionals and volunteers have limited STEM subject matter experience and knowledge (Barker et al., 2009; Laursen et al., 2013).

To meet this challenge, organizations like 4- $\mathrm{H}$ are expanding their volunteer models to engage highly trained volunteers such as faculty and professionals to offer technical STEM programs (Riley \& Butler, 2012; Veleva et al., 2012). Working with these "corporate volunteers" also presents unique challenges such as the need for youth development training and communication skills (Smith \& Schmitt-McQuitty, 2013). Furthermore, it can be difficult to find and recruit qualified science context experts to volunteer for these programs (Turnbull, 2013). Therefore, it is critical that youth organizations identify solutions to support volunteers' competence and ability to lead quality STEM projects.

\section{4-H Science: Building a 4-H Career Pathway Initiative}

Findings discussed here are from the 4-H Science: Building a 4-H Career Pathway Initiative. This was a 3-year collaboration among National 4-H Council, Lockheed Martin, and 13 land grant universities that provide 4- $\mathrm{H}$. The overall goal was to involve more girls and minorities in 4-H STEM programs to create a robust pipeline to STEM-advanced education and careers. Significant human capital from 4-H professionals, Lockheed Martin employees who served as corporate volunteers, and $4-\mathrm{H}$ community volunteers contributed to this initiative. States collectively reached 89,291 youth and engaged 521 Lockheed Martin corporate volunteers and 3,679 community volunteers in 4-H STEM projects (Donaldson \& Franck, 2018). States were divided into two cohorts for this initiative. Cohort 1 consisted of three states who were expected to provide intensive STEM activities that included internships, job shadowing opportunities, and STEM clubs that provided long-term engagement. Cohort 2 included 10 states that were expected to provide 1-day STEM-focused workshops to youth with the hope that these activities 


\section{Volunteer Training Needs for 4-H STEM Programs}

might interest youth in exploring more intensive 4-H STEM clubs and projects. Only data from the three Cohort 1 states are included in this paper because participants from these states had more long-term experiences with the initiative including feedback about volunteer involvement.

A process evaluation was conducted to explore project implementation and to inform recommendations for potential approaches to produce and deliver quality 4-H STEM programs. The specific objective related to the volunteer aspect of the project was to identify barriers and potential solutions to overcome those barriers for volunteers to successfully deliver 4-H STEM programs.

\section{Methods}

This qualitative study included individual and focus group interviews that employed the grounded theory approach (Creswell, 1998). Focus groups were selected because this method provides depth and breadth of information as well as viewpoints and impressions (Krueger \& Casey, 2015; Mertens, 2010). When focus groups were not feasible, such as when there were fewer than five participants, individual interviews were conducted. This study was approved by the University of Tennessee Institutional Review Board (UTK IRB-15-02714-XP).

\section{Participants}

Focus groups and individual interviews were conducted in the three Cohort 1 states. In each state, the 4-H professionals who were the Principal Investigator (PI) or Project Director (PD) for this 4-H STEM initiative recruited participants for the focus groups and interviews. The researchers instructed the PI/PDs to recruit participants who were actively involved in a 4-H STEM project that was funded as part of the initiative. All participants signed consent forms before the interview or focus groups started. Youth participants signed assent forms and their parents signed parental consent forms. For this study, there were 149 participants: 26 were interviewed individually and nine focus groups were conducted. (Table 1).

Three focus groups were conducted with both $4-\mathrm{H}$ youth and parents. For the parent and youth focus groups, parents had the option to attend the focus group with their child(ren), so some children did not have a parent present. For the three groups, there were more children present than parents. The researchers introduced the focus group to facilitate open discussion by instructing parents and youth that their opinions are important and that there were no right or 


\section{Volunteer Training Needs for 4-H STEM Programs}

wrong answers to the questions. The researchers used techniques to help youth feel comfortable sharing such as asking youth to answer a question first, then asking parents to answer, then asking the entire group if there were any more discussion. When interviews were conducted, youth were interviewed without their parents present. Separate focus groups were conducted for community volunteers, corporate volunteers, and 4-H professionals.

Table 1. Participants in Focus Groups and Individual Interviews

\begin{tabular}{|l|c|c|c|c|c|}
\hline & $\begin{array}{c}4-H \\
\text { youth }\end{array}$ & $\begin{array}{c}4-H \\
\text { parents }\end{array}$ & $\begin{array}{c}\text { Community } \\
\text { volunteers }\end{array}$ & $\begin{array}{c}\text { Corporate } \\
\text { volunteers }\end{array}$ & $\begin{array}{c}\text { 4-H } \\
\text { professionals }\end{array}$ \\
\hline Individual interviews & 8 & 7 & 8 & 0 & 3 \\
\hline Focus group participants & 32 & 19 & 5 & 7 & 53 \\
\hline Number of focus groups a & 3 & 3 & 1 & 1 & 4 \\
\hline
\end{tabular}

${ }^{a}$ Focus groups were conducted with parents and youth together for a total of 3 focus groups.

\section{Procedures}

The researchers developed a script and discussion questions based on previous studies with 4-H youth and professionals. These questions were designed to generate group engagement and discussion about 4-H STEM programs. The researchers asked the same questions for both individual and focus group interviews. Sample questions included:

- Would you recommend this program to other youth and families? Why or why not? (4-H youth and parents)

- What would make this program better? (volunteers)

- Talk about your most recent activity related to 4-H Science: Building a 4-H Career Pathway Initiative. Who was involved? What happened? (4-H professionals)

Individual interviews took about 20 minutes and focus groups lasted for about 1 hour.

\section{Data Analysis}

The focus groups and individual interviews were audio recorded and were transcribed verbatim. The researchers used NVivo to mine the data, to create categories and to tag the data (Creswell, 1998). An open coding-approach was employed as the groups were analyzed separately and then the categories were aggregated (Creswell, 1998; Krueger \& Casey, 2015). Because this project was a process evaluation, once data were collected they were coded and 


\section{Volunteer Training Needs for 4-H STEM Programs}

analyzed to inform program improvement. The two researchers independently coded the transcripts and then jointly reviewed their findings. Any discrepancies were discussed to reach consensus. Related to data about volunteers, the initial categories were divided into challenges/barriers and successful practices. Challenges and barriers included several subcategories about issues related to training needs. Both categories (challenges/barriers and successful practices) included issues related to volunteer recruitment and retention. The final data were aggregated across years and groups using these categories and subcategories.

\section{Findings}

Major themes were identified related to barriers and challenges for recruiting, engaging, and working with volunteers in 4-H STEM programs. In addition, practices were identified that had been utilized by $4-\mathrm{H}$ professionals to overcome those barriers. Several ideas that could be implemented to overcome challenges were also described.

\section{Barriers for Working With Volunteers in 4-H STEM Programs}

Several themes emerged related to the challenge of working with volunteers to deliver 4-H STEM programs. These included the limited STEM knowledge of traditional 4-H volunteers, the limited knowledge of youth development and teaching skills for scientists who were interested in becoming volunteers, and the difficulty of recruiting and retaining 4-H volunteers who were skilled in STEM or were willing to complete STEM training.

\section{Limited STEM Knowledge of 4-H Volunteers}

Youth and 4-H professionals discussed that many traditional 4- $\mathrm{H}$ volunteers had limited science knowledge and expertise, and this was a barrier for implementing and expanding 4-H STEM programs. As one 4-H professional stated: "A lot of our traditional 4-H volunteers are still scared to death of science. I mean they're afraid of it because it's not a subject that's traditionally . . . been in 4-H." Youth talked about being in 4-H clubs that were led by parents who wanted to support the youths' interest in STEM but had little training or expertise in the subject matter. Representative comments included:

- "I find that a lot of older people don't know [STEM] as well. They're very intimidated, and they don't want to step into leadership they don't understand."

- "Volunteers may think that they want to do it, but ... they're uncomfortable that they don't know it, and they feel like they've got to become the expert before they can teach 


\section{Volunteer Training Needs for 4-H STEM Programs}

it. So they never get comfortable enough with it to get a good program started. They're not comfortable with just being, you know, a week or two ahead of the students."

- "My club almost just got shut down . . . because nobody was willing to lead it because everybody was either getting too old and retiring or they were just done with it. And so we just got one of the moms to do it, so she knows nothing."

Furthermore, 4-H professionals discussed that some parents and youth expected 4-H STEM programs to be coordinated and led by science experts. This included the feeling that parents would not be comfortable with volunteers who were learning alongside the youth as one 4-H professional described this interaction with a parent: "She told me when I bring my kids to something like [4-H STEM] I don't want to feel like the person is just learning to do it. I want to know they have a level of expertise with doing it."

For 4-H professionals, their own lack of STEM knowledge and competence in these areas limited their confidence to lead 4-H STEM efforts as described in this statement:

All our employees are adaptable, but it would also be nice to have a training on the foundation of physics or mechanics or basic engineering concepts, so that whenever I go out to teach robotics or whenever they go out to teach aerodynamics or whatever the latest, greatest lesson is, that we have a leg to stand on that makes us more credible.

This lack of confidence related to STEM knowledge limited 4-H professional's ability to provide guidance and support to volunteers. Comments included:

- "We have volunteers that come in that are very interested in getting started, but then it's how do you support them when they get beyond those basics."

- "We could teach [volunteers] how to teach it, but we can't teach them the expertise."

- "I always see myself in [volunteers], and when I ask them to do it, like what am I asking because like we all have our niche that we are good at. But we're telling them to teach the kids, and that means they have to know what they are doing."

\section{Limited Youth Development and Teaching Skills for Potential Volunteers}

4-H professionals and corporate volunteers identified the importance of STEM experts being able to teach and lead youth projects. 4-H professionals talked about experiences working with scientists who struggled to engage youth audiences. 4-H professionals valued the expertise that 


\section{Volunteer Training Needs for 4-H STEM Programs}

these scientists could bring to STEM programs, but they also identified the difficulty that many of these volunteers had when teaching youth as illustrated in these comments:

- "When we find that expert, they can't talk to the kids. They want to pile on all the information at once, and that's when the kids get overwhelmed."

- "If you've got the volunteers who are willing to work with the youth a lot of times they don't have the expertise, but the ones with the expertise, I don't know how we get them and help them become better educators."

Corporate volunteers (who were all STEM professionals) also recognized their own limitations with pedagogy and youth development. Representative comments included:

- "I remember the first time I went into [agency]. I'd put a PowerPoint up and lost half of them about slide two or something. So I had the best intentions, but you have to know how to work with every different audience, and I think . . . training [related to working with youth groups] is a very event-specific thing because it could be a different audience one time versus the next time."

- "Break it down by age group like for the Science Day. We didn't know the age group; it was like such a wide range. And it would have been helpful if there's about five in this group and ten in this group, and then maybe some common behaviors for that group."

In addition to general knowledge about how to engage and teach youth, 4-H professionals felt that 4-H STEM volunteers needed to allow youth more space to explore and try new ideas as described here: "[Volunteers] really feel like they've got to structure everything, and they don't get the exploration part that we're trying to get [youth] to." Other topics included training related to how to work with challenging parents and how to address common behavior issues.

\section{Recruiting and Retaining Volunteers}

4-H professionals talked about how difficult it was to recruit and retain volunteers overall, but these issues seemed magnified in some STEM programs. Some of the issues were around the volunteer training needed to increase confidence related to STEM skills. There was the perception that this training would be more time-intensive and challenging compared to other subject matter areas. Comments included

- "We hit a turnover with our volunteers, and we've had a very strong program, but literally nobody wants to take the training necessary to continue on with the program. And we've run an ad, we've offered possibly a stipend, and people really just did not want to take that level of training." 
- "So kind of accommodating their needs and their interests and also supporting with the proper training and guidance so that it isn't so heavily involved for volunteers to take it and make it something that's enjoyable for them."

\section{Potential Solutions for Working With Volunteers in 4-H STEM Programs}

Participants also identified several solutions for overcoming barriers for working with volunteers to deliver quality 4-H STEM programs. Some of these ideas had been implemented successfully in this initiative and some were potential solutions to be considered. Themes included: the incorporation of different levels of volunteer training related to STEM knowledge and utilizing diverse models to recruit volunteers to lead and support 4-H STEM programs.

\section{Volunteer Training Tailored to Meet the Needs for Community and Corporate Volunteers}

4-H professionals as well as community and corporate volunteers acknowledged different training needs in order to increase the quality of 4-H STEM programs. For community volunteers, 4-H professionals identified the need for training to increase STEM knowledge as a priority to engage more volunteers to expand capacity for 4-H STEM programs. 4-H professionals talked about the need to develop different levels of STEM training for volunteers that could also be used with 4-H professionals. These levels ranged from basic science skills to more advanced topics. Several participants talked about how these trainings needed to be hands-on and interactive as much as possible to increase confidence for volunteers and $4-\mathrm{H}$ professionals about their ability to teach STEM skills to youth.

In addition, 4-H professionals also expressed the need for volunteer training to be ongoing so volunteers could learn new information related to science to help deliver relevant and timely programs for youth. Many participants also talked about the challenge of staying up-to-date since they perceived that STEM knowledge and projects often involved complex skills that were changing rapidly. For example, one 4-H professional talked about teaching robotics: "There's so many things and so many levels that you're never quite done learning."

Prepackaged programs were another suggestion for overcoming limited science skills for volunteers. Several participants talked about the National Youth Science Day curriculum as well as other 4-H STEM products. 4-H professionals and both community and corporate volunteers discussed how helpful it was to have kits that included facilitator manuals with hands-on, interactive science projects. Comments included: 


\section{Volunteer Training Needs for 4-H STEM Programs}

- "If we can come up with age-specific material that teach certain elements of science that we can almost have ready kits or be able to put together simple kits to use. That would kind of empower [volunteers] to run with it."

- "Here's a kit and you go and deliver it and you know, it can be done in $\mathrm{x}$ amount of time. The teachers like that because they like those short, sweet, simple activities and lessons that kind of get them moving."

4-H professionals and corporate volunteers identified training related to teaching youth and engaging youth audiences in STEM as a critical need. As discussed previously, corporate volunteers identified their challenges related to tailoring scientific materials to meet the needs of youth audiences and engaging youth of different ages. Corporate volunteers also acknowledged how helpful prepackaged programs could be, especially programs that provided teaching tips for working with specific age groups.

\section{Diverse Models for STEM Volunteer Recruitment.}

4-H professionals and corporate volunteers proposed different ideas for how to recruit volunteers in order to expand 4-H STEM programs. Corporate volunteers were an important part of this initiative. Although there were challenges engaging corporate volunteers, 4-H professionals identified the many benefits of working with these professionals in 4-H STEM programs. Challenges included balancing work expectations with volunteer opportunities and providing incentives for professionals to devote time to volunteer for 4-H STEM programs. 4-H professionals talked about the need to be flexible when working with corporate volunteers especially when projects happened during work hours. Successful programs looked for volunteer opportunities that would benefit both the program and the corporate volunteers. For example, some Lockheed Martin sites allowed corporate volunteers to work with youth as part of their job and encouraged these opportunities. Corporate volunteers talked about the importance of their company communicating with employees about volunteer opportunities through newsletters, websites and social media.

4-H professionals identified several professional groups that were successful resources for engaging STEM experts. This initiative focused on increasing participation of girls and minority youth in 4-H STEM programs, so many of these organizations supported women and ethnic groups. Groups that were engaged through this initiative included the Society of Women Engineers and the National Society of Black Engineers. Members of these organizations provide 


\section{Volunteer Training Needs for 4-H STEM Programs}

outreach and volunteer service, and some 4-H professionals for this initiative were able to form strong partnerships with these groups to enhance 4-H STEM programs.

4-H professionals in one state discussed a volunteer model that included working with faculty and college students. The 4-H professionals engaged faculty in short-term volunteer opportunities such as seminars and 1-day events. College students delivered semester-long STEM programs for youth, which offered the youth longer-term STEM learning experiences and provided the volunteers with first-hand teaching experiences that counted as course credit. Other college students were engaged through service groups such as Engineers without Borders. 4-H professionals felt that younger volunteers were important role models for $4-\mathrm{H}$ youth: "As far as the college kids, it actually helps expose the youth to what it's like to be on a college campus. It makes the youth excited about that because they get to work with somebody closer to their age."

Virtual volunteer engagement was suggested by several participants especially in rural areas where there often is limited access to science experts. One state involved in this initiative had virtual webinars, where corporate volunteers engaged with $4-\mathrm{H}$ youth on different STEM topics. Other suggestions included virtual tours of corporations and college science departments to show 4-H youth different potential careers and educational options.

\section{Discussion, Implications, and Conclusions}

Although this study was in the context of $4-\mathrm{H}$, the results have implications for the broader cadre of youth organizations delivering STEM education. These youth-serving organizations have the potential to help strengthen science knowledge and skills for youth. Yet, as demonstrated in this 4-H STEM study, the success of these programs is dependent on the ability of volunteers and professionals to effectively engage and encourage youth (Larson Nippolt, 2012). Ideally, STEM programs would be led by science experts who are able to effectively teach youth in a manner consistent with recommendations by Riley \& Butler (2012). However, findings from this initiative underscore the fact that access to science experts who are willing and able to lead youth STEM programs varies by location, and recruitment of these science experts is a major challenge for $4-\mathrm{H}$ professionals.

4-H professionals could benefit from training related to how to recruit science experts to serve as volunteers. Volunteer recruitment methods need to be diverse in order to attract and engage 
science experts. This initiative had several examples that worked well, including engaging corporate volunteers, enlisting universities and colleges to work with faculty and college students, and partnering with science service organizations. 4-H and other youth organizations need to continue to develop relationships with corporations like Lockheed Martin, academic science departments, and other industry leaders to work together to provide incentives to entice scientists to volunteer their time for youth STEM programs. There is the need to jointly market these volunteer opportunities to increase awareness and to demonstrate the employers' commitment to these programs.

Findings from this initiative indicate that college students who volunteer for STEM programs provide important encouragement for youth to pursue higher education opportunities. Exploring relationships with community colleges as well as colleges and universities could help increase the number of college students who volunteer for these programs. Furthermore, other academic organizations like service clubs, sororities, and fraternities could encourage college students to assist with youth STEM activities.

There is potential for virtual volunteer experiences that could strengthen 4-H STEM programs. One such innovative program is Follow a Researcher, which uses social media and satellite technology to pair youth with graduate students conducting scientific research (Wilson et al., 2018). It is important that youth organizations like 4-H continue to identify and develop best practices as well as resources for professionals to successfully implement different volunteer models. While it is not feasible for science experts to directly teach all youth, an online volunteer training clearinghouse is an option that youth development organizations could explore collectively. Such a clearinghouse could provide direct instruction from science experts to volunteers across youth development organizations and could provide a system to "match" volunteers to youth organizations.

Professional development is critical to "level-up" the STEM skills of 4-H professionals and traditional 4-H volunteers (Worker et al., 2017). This training is imperative for 4-H professionals so that they can increase competence and confidence when supporting volunteers who are working with 4-H STEM programs. Additional volunteer training is needed that focuses on youth development and pedagogy. Many science experts also need training and mentoring to help them adapt and translate their technical content so that it is accessible to youth audiences. Volunteer training opportunities that include the use of hands-on, easy-to-use, science curricula and demonstration projects were suggested as ways to help volunteers without a science 


\section{Volunteer Training Needs for 4-H STEM Programs}

background feel more comfortable with the subject matter as well as ways to help volunteers with a science background feel more comfortable engaging youth. Mentorship opportunities for volunteers could also help strengthen STEM programs by providing volunteers with access to science experts who could offer technical assistance and support.

Because of needed time and resources to conduct quality STEM programs, best practices indicate that there needs to be dedicated staff to provide oversight to these programs. One of the Cohort 1 states included in this paper had a state-level 4-H professional who provided guidance and support to STEM programs. This staff person was able to coordinate statewide trainings both for $4-\mathrm{H}$ professionals as well as for potential volunteers and provided ongoing support and technical assistance. It is important that STEM staffing continues in 4-H and that these professionals receive training related to recruiting and retaining science experts as volunteers. In addition, these professionals need training about how to develop and form relationships with STEM-focused corporations and service organizations to encourage more corporate volunteerism.

In conclusion, 4-H STEM programs have the potential to encourage youth to explore advanced STEM education and careers to meet the growing workforce demand of these programs. Volunteers have an important place across 4-H programs including STEM. It is important that 4$\mathrm{H}$ programs support and enhance these volunteer experiences to continue to strengthen STEM opportunities for youth.

\section{Acknowledgements}

We are grateful to National 4-H Council and Lockheed Martin for funding this project.

\section{References}

Barker, B. S., Grandgenett, N., \& Nugent, G. (2009). A new model of 4-H volunteer development in science, engineering, and technology programs. Journal of Extension, 47(2). https://www.joe.org/joe2009april/2iaw4/php

Creswell, J. W. (1998). Qualitative inquiry and research design: Choosing among five traditions. Sage. Donaldson, J. L. \& Franck, K. L. (2018). 4-H science: Building a 4-H career pathway initiative (Final Evaluation Report, W 668). University of Tennessee Extension. https://extension.tennessee.edu/publications/Documents/W668.pdf 
Journal of Youth Development | http://jyd.pitt.edu/ | Vol. 15 Issue 4 DOI 10.5195/jyd.2020.856

Volunteer Training Needs for 4-H STEM Programs

Heck, K. E., Carlos, R. M., Barnett, C., \& Smith, M. H. (2012). 4-H participation and science interest in youth. Journal of Extension, 50(2). https://www.joe.org/joe/2012april/a5.php

Krueger, R. A., \& Casey, M. A. (2015). Focus groups: A practical guide for applied research. Sage.

Larson Nippolt, P. (2012). 4-H science: Evaluating across sites to critically examine training of adult facilitators. Journal of Youth Development, 74). https://doi.org/10.5195/jyd.2012.114

Laursen, S. L., Thiry, H., Archie, T., \& Crane, R. (2013). Variations on a theme: Characteristics of out-ofschool time science programs offered by distinct organization types. Afterschool Matters, 17, 3649. https://files.eric.ed.gov/fulltext/EJ1003841.pdf

Mertens, D. M. (2010). Research and evaluation in education and psychology: Integrating diversity with quantitative, qualitative, and mixed methods ( $3^{\text {rd }}$ ed.). Sage.

National Informal STEM Education Network (2015). Profiles of national youth-serving organizations: Collaborating with youth-serving organizations on STEM activities locally. https://www.nisenet.org/sites/default/files/Profiles\%20national\%20youth\%20serving\%20organiz ations\%2011-28-15\%20FINAL.pdf

Riley, D., \& Butler, A. (2012). Priming the pipeline: Lessons from promising 4-H science programs. Policy Studies Associates.

Rothwell, J. (2014). Still searching: Job vacancies and STEM skills. Metropolitan Policy Program at Brookings. Retrieved January 26, 2018 from https://www.brookings.edu/wpcontent/uploads/2014/07/Job-Vacancies-and-STEM-Skills.pdf

Smith, M. H., \& Schmitt-McQuitty, L. (2013). More effective professional development can help 4-H volunteers address need for youth scientific literacy. California Agriculture, 671), 47-53.

Turnbull, B. J. (2013). The 4-H science initiative: Summary observations from an evaluation. https://4h.org/wp-content/uploads/2016/02/4-H-Science-Initiative-PSA-Summary-Report.pdf

Veleva, V., Parker, S., Lee, A., \& Pinney, C. (2012). Measuring the business impacts of community involvement: The case of employee volunteering at UL. Business and Society Review, 11入1), 123-142.

Wilson, L., Lobley, J., \& Kranich, G. (2018). Follow a Researcher: Using innovative technology to connect youths and scientists. Journal of Extension, 56(5). https://www.joe.org/joe/2018september/5tot3.php

Worker, S. M., Schmitt-McQuitty, L., Ambrose, A., Brian, K., Schoenfelder, E., Smith, M. H. (2017). Multiple-methods needs assessment of California 4-H science education programming. Journal of Extension, 55(2). https://wwwl.joe.org/joe/2017april/rb4.php 